with but a trifling delay, and entirely without pain, the man stating immediately afterwards that he had felt me touching him, but had no idea I was removing the tumour. The incision was four inches long, and the muscles on its floor were completely laid bare.

I am, Sir, your obedient servant,

Birmingham, March 14th, 1866.

J. SAMPSON GaMgeE.

\section{MEDICAL EDUCATION IN FRANCE AND ENGLAND.}

To the Editor of THE LANCET.

SiR, - It is with no little astonishment that I have just read, in The Lancet of the 3rd inst., a letter signed "M. B." The writer asserts that, having lately returned from Paris, he has had full opportunity of comparing the system of medical education pursued by what he incorrectly terms the University of Paris with that of the University of London. He must have availed himself but poorly of such opportunity, for that which he affirms is completely contrary to fact.

It is not true that in Paris the examination in anatomy is not on the dissected subject, nor is it true that " the student is only occasionally required to show his knowledge of anatomy practically by tying an artery, or by some other operation." Nine years of medical study in the French capital, perhaps, entitle me to write with some authority on this subject. On the day of examination in anatomy the candidate is summoned to the Ecole Pratique at eight o'clock in the morning, and there, shut up in a room, four hours' dissection (without books) are allowed him for making a preparation, which is submitted to the examiners, and on which he is questioned by them. Afterwards, in order to test more fully his ready, practical knowledge of anatomy, he is required to cut down and show an organ, such as nerve, artery, \&c., in different parts of the dead body. This is followed by the viva voce examination. Possibly "M. B." may have been present at the second examination for the Doctorat (on internal and external pathology), at the commencement of which the student is required to perform at least two operations on the dead body ; and this "M. B." may have imagined to be the examination in anatomy. What he says with regard to the option of "taking the four final examinations, each consisting of a single subject, at one and the same time," is quite unintelligible to those conversant with the Parisian system of examination. In order that your numerous readers may not be misinformed, will you allow me to say that each of the four final examinations comprehends three subjects, and there must of necessity be an interval between them.

On two occasions only the candidate has to make a written epreuve. The first is during the fourth examination, when he has to write a medico-legal report on a subject given to him by the examiner; and the other is before the fifth examination, when two hours are allowed him for writing on a subject in internal or external pathology, also named by the examiner. With these exceptions, all the nine examinations are carried on vir $\vec{a}$ voce, and before the public. To pass them successfully under such circumstances, the candidate must not be wanting in learning nor self-possession, qualities which are essentially necessary to the doctor. When the former is present the latter is rarely absent. It is a question whether these viv $\hat{a}$ voce and public examinations do not afford a better guarantee for the efficiency of the candidate and impartiality of the juciges than those which are carried on vivê voce, and more especially through the means of written papers, within closed doors.

I am, Sir, yours obediently, W. H. Jones, M.D. Paris.

Hanover-street, Hanover-square, March, 1866.

\section{ON THE INTRODUCTION OF PEROXIDE OF HYDROGEN AS A MEDICINE.} To the Eiditor of THE LANCET.

SIR,-I have read with interest, in THE LANCET of the 3 rd inst., Dr. Goolden's letter on the "Treatment of Disease by oxygen." An allusion in that letter to my researches requires correction.

Dr. Goolden says :- " For the method of obtaining this pre- paration, peroxide of hydrogen, in its present perfection, $I$ be lieve we are indebted to Dr. Richardson." This is an im. perfect reading of the facts. The peroxide of hydrogen, made at my instance for medicinal purposes, and now so largely manufactured by Mr. Robbins of Oxford-street, is prepared on and by the original process of the illustrions discoverer of the peroxide of hydrogen, the French chemist, Thénard.

The credit, if there be any, that is due to me in respect to the use of this substance as a medicine, rests on the circumstances :-(1) That I was the first experimentalist who investigated the physiological properties of the peroxide of hydrogen. (2) That I drank the first doses of it to test what could be borne by the human subject. (3) That I determined what volumetrical strength of the solution could be practically em ployed in medicine. (4) That as a remedy for disease, I in. troduced it originally into practice.

Thénard, I believe, looked upon the discovery of peroxide of hydrogen as one of the most important of his labours ; and I have sometimes thought that when the medicinal value of the substance is properly known, my own labours in this waylabours which extended from 1859 to $1863-$-will be recognised. I am, therefore, anxious that my part in the work should be correctly understood and clearly defined.

I remain, Sir, your most obedient servant,

Hinde-street, W., March 10th, 1866 B. W. RICHARDsor, M.D.

\section{THE EXPANDING UTERINE STEM. To the Editor of The LANCET.}

SIR, -The "new instrument" delineated by Dr. Henry G. Wright in your journal of the 24th of February last, closely resembles in principle and construction one made at my suggestion by Messrs. Weiss, on the 2 nd of March, 1864, and described by Dr. Routh in his pamphlet "On the Use of the Hysterotome in certain forms of Uterine Disease," page 17 , published during the same year, and more recently, somewhat modified, by Dr. Marion Sims, at pages $404-5$ of his recent work. My bilateral expanding stem was exhibited at the Obstetrical Society, and also by Dr. Routh at the meeting of the British Medical Association at Cambridge. Moreover, I informed Dr. Wright of the nature and date of my invention prior to the publication of his communication in your journal. This stem has been used in the Samaritan Hospital, of which Dr. Wright is one of the medical officers, and frequently in St. Bartholomew's Hospital before my class, and by numerous medical men in public and private practice in this coun. try and on the Continent. Having mentioned these few facts, I leave your readers to draw their own inferences as to Dr. Henry G. Wright's "new instrument." I may also mention that Dr. Aveling exhibited at the meeting of the Obstetrical Society, held July 5th, 1865 , "an intra-uterine spring tent." I am, Sir, your obedient servant,

Grosvenor-street, March, 1866. RoBert GreenhaLGH, M.D.

\section{THE NEW UTERINE DILATOR.} To the Editor of The Lancet.

SIR,-As I consider Mr. Pratt's communication, in your last number, calculated to impress your readers with the idea that the instrument he made for Dr. Sims is identical with mine in all respects, I shall feel much obliged if you will insert these few lines in explanation. I have called on Mr. Pratt, and he kindly allowed me to examine Dr. Sims' dilator, to which he referred in his note to you, and I find that it is identical with mine only in one particular-namely, that they both have a triple hinge at the extremity, and both thereby produce complete dilatation of the internal os ; in all other respects they are totally dissimilar. My first intimation of the existence of Dr. Sims' instrument was Mr. Pratt's communication to you last week ; I find that my instrument was completed before that made by Mr. Pratt, and I, with Dr. Sims, claim originality as regards the one point of similarity. For the respective advantages of the remaining details and modifications in construction, I refer those interested in the matter to a comparison of the two instruments.

I am, Sir, yours obediently, J. WILLIAM HeMbRougr

March, 1866. Resident Accoucheur to St. Bartholomew's Hospital. 